\title{
Perfil Esquemático das Fitofisionomias Ecológicas do Extremo Sul do Estado de Santa Catarina
}

\author{
Weslley Luan Soares $^{(\mathrm{a})}$, João Paulo Oliveira da Rosa ${ }^{(\mathrm{b})}$, Hariany Cargnin $^{(\mathrm{c})}$, Jairo Valdati $^{(\mathrm{d})}$ \\ (a) Departamento de Geografia/FAED, UDESC, weslley850@ hotmail.com \\ (b) Departamento de Geografia/FAED, UDESC, joaopauloor1996@gmail.com \\ (c) Departamento de Geografia/FAED, UDESC, harianyscargnin@gmail.com \\ (d) Departamento de Geografia/FAED, UDESC, javaldati@ hotmail.com
}

\section{EIXO: BIOGEOGRAFIA, MANEJO DE ÁREAS NATURAIS E PROTEGIDAS: CONSERVAÇÃO DA BIODIVERSIDADE}

\begin{abstract}
Resumo:
O objetivo deste artigo é apresentar, através de descrição, juntamente com a ilustração por meio de um perfil fitofisionômico, as formações vegetais da região do Extremo Sul do Estado de Santa Catarina. Para isso foram utilizadas bibliografias especializadas, a ferramenta "Interpolate line" do ArcMap 10.1 para a geração de um perfil topográfico e expedições in loco. A partir deste trabalho, ressalta-se a importância do perfil fitofisionômico como instrumento na representação da vegetação, principalmente em áreas com diferenças topográficas acentuadas, bem como instrumento para estudos de preservação de remanescentes vegetais e como método didático para o ensino das diferentes formações vegetais.
\end{abstract}

Palavras chave: Perfil Fitofisionomico; Mata Atlântica; Remanescentes; Extremo sul de Santa Catarina.

\section{Introdução}

Apesar do estado de Santa Catarina ter um território relativamente pequeno em relação a outros estados (compreende cerca de $1 \%$ do território brasileiro), e estar totalmente situado no bioma das Florestas Tropicais, sua vegetação apresenta grande variedade, devido, em grande parte, pelas suas diversas características climáticas e orográficas.

O objetivo deste trabalho é apresentar, através de descrição, juntamente com a ilustração através de um perfil fitofisionômico, as formações vegetais da região do Extremo Sul do Estado de Santa Catarina, abrangendo desde a faixa litorânea, passando pela planície costeira e chegando ao Planalto Meridional Sul brasileiro, localmente conhecido como Serra Geral, com suas escarpas bem evidentes na paisagem local.

Essa região é particularmente interessante para uma análise biogeográfica de vegetação, pois dentro da extensão do perfil topográfico apresentam-se todas as formações vegetais encontradas no estado catarinense, que é compreendida pelos (1) sistemas edáficos de primeira ocupação (restingas, manguezais 
e comunidades aluviais) e (2) Floresta Ombrófila Densa (Mata Atlântica) na planície costeira e encostas da Serra Geral; (3) Floresta Ombrófila Mista (Mata de Araucária) e as (4) Estepes (Campos do Sul do Brasil), no alto do planalto, além de haver nela uma formação vegetal muito particular, rica em espécies endêmicas, a Mata Nebular. A única formação que não está situada dentro deste espectro topográfico é a Floresta Estacional Decidual e Semidecidual, que por sua vez é encontrada apenas na região oeste, sobretudo na bacia do rio Uruguai.

\section{Materiais e Métodos}

Inicialmente foi produzido o perfil topográfico utilizando as ferramentas disponíveis do ArcMap 10.1. Através do MDT da área de estudo juntamente ao mapa base, foi traçada uma linha que liga a costa litorânea, passando pela planície, subindo a escarpa até adentrar o início do planalto usando a ferramenta "Interpolate Line", que cria feições em 3D a partir da interpolação de uma linha sobre uma superfície e registrando suas diferentes altitudes, e assim, gerando o perfil topográfico.

As descrições das fisionomias vegetais foram feitas a partir de trabalhos de campo, através da identificação dos remanescentes da vegetação original e consulta à literatura especializada. Para a distinção entre as diversas formações vegetais seguiu-se o proposto pelo Manuel Técnico da Vegetação Brasileira (IBGE, 2012).

A ordem descritiva de cada formação vegetal segue o sentido leste para oeste. A representação das formações vegetais sobre o perfil foi elaborada manualmente através do uso de lápis de cor, gerando assim um perfil fitofisionômico.

\section{As Formações Vegetais Originais do Estado de Santa Catarina}

De acordo com IBGE (2012), dentro das formações pioneiras, são encontradas vegetações com influencia marinha (Restinga), vegetações com influencia fluvio-marinha (Maguezais) e vegetações com influencia fluvial (Comunidades Aluviais).

Nas baías e desembocaduras dos rios desenvolvem-se os Manguezais, com predominância de espécies de porte arbustivo além de pequenas árvores, adaptadas à salinidade da água, como a Avicennia schaueriana, popularmente chamada de Siriúba (KLEIN, 1978).

As Restingas são encontradas nos terrenos arenosos e recebem influencia direta das águas do mar (IBGE, 2012). Essa formação estabelece-se em terrenos firmes, ou seja, nas planícies de Restinga e em terrenos 
instáveis, principalmente campos de dunas. Nas dunas semifixas dominam as espécies Aroeira-vermelha (Schinus terebinthifolius) e o pau-de-bugre, ou Lithraea brasiliensis (KLEIN, 1978). Nas planícies de restinga, onde o solo é mais firme, predominam guamirins (Eugenia sp.) e o Cambuí ou Myrcia multiflora (KLEIN, 1978).

Já as Comunidades Aluviais refletem os efeitos das cheias dos rios, em determinadas épocas do ano e de depressões alagáveis, durante todo o ano (IBGE, 2012). Como o próprio nome já diz, essa vegetação é encontrada em ambientes aluviais, com presença constante de água doce, seja rios, lagos e lagoas.

Cobrindo a Planície Costeira e avançando continente adentro, até as mais altas montanhas da Serra Geral, encontra-se a Floresta Ombrófila Densa, popularmente conhecida como Floresta ou Mata Atlântica.

Voltada para o Oceano Atlântico, essa formação vegetal é condicionada pela umidade e pelo clima quente (SEVEGNANI, LAPS, SCHROEDER, 2013). Pelo motivo de ser fortemente determinada pelas abundantes chuvas dessa região, em sua nomenclatura está a palavra Ombrófila, de origem grega, que significa "amiga das chuvas" (IBGE, 2012).

Sem dúvidas é a floresta mais abundante e mais complexa, formada por diversos agrupamentos (KLEIN, 1978), além de uma estrutura de estratos completa e uma miríade de espécies ímpar no mundo. Vale ressaltar que é considerada a floreta mais biodiversa do planeta Terra.

Ocupando 1/3 da superfície do estado, a Floresta Ombrófila Densa é composta por densas comunidades arbóreas, possuindo árvores suntuosas que chegam medir 30 a 35m de altura (KLEIN, 1978). Tem um caráter sinusial, ou seja, estratos bem definidos. Esses estratos bem desenvolvidos são a principal característica dessa formação. A floresta possui também uma quantidade bastante considerável de epífitas, como as Bromeliaceas, Orquidáceas, Aráceas, etc. Além de um grande número de lianas lenhosas (KLEIN, 1978).

Esse tipo vegetacional da Floresta Ombrófila Densa é subdividida em 5 (cinco) grupos, que possuem características fisionômicas distintas (IBGE, 2012). A grande condicionante ambiental para essas subdivisões é a altitude, pois a cada $100 \mathrm{~m}$ a temperatura diminui $1{ }^{\circ} \mathrm{C}$. Levando em consideração que a topografia da região Sul do estado é amplamente variável, possuindo um acentuado gradiente de declividade entre as planícies da costa e o alto do Planalto, as médias de temperatura também variam consideravelmente, resultando em fisionomias vegetais distintas, mesmo sendo todas elas parte de uma mesma formação.

Nas áreas mais baixas encontra-se a Floresta Ombrófila Densa Aluvial, de formação ribeirinha, é a mata ciliar que acompanha o curso dos rios, ocupando terraços e planícies quaternárias (IBGE, 2012). 
Em altitudes inferiores a 30m, ocupando os terrenos formados e nivelados pelos avanços e recuos do nível do oceano nos últimos cinco milhões de anos, estão as formações de Floresta Ombrófila Densa de Terras Baixas (SEVEGNANI, LAPS, SCHROEDER, 2013). Com árvores de até 20m, possui muitos palmiteiros, arvoretas e arbustos, além de bromélias no solo. Destaca-se também árvores como a Copiúva (Tapirira guianensis), a Figueira (Ficus organensis) e o Coqueiro-gerivá (Syagrus romanzoffiana).

Na costa litorânea catarinense, a formação das Terras Baixas entra em contato com os Sistemas Edáficos de Primeira Ocupação, principalmente a vegetação de Restinga e Comunidades Aluviais, ficando, muitas vezes, difícil discernir os limites entre essas distintas formações (SEVEGNANI, LAPS, SCHROEDER, 2013).

Nas altitudes de 30 a 400m a Floresta Ombrófila Densa é Submontana. Presente em áreas com solos profundos e estruturados, boa drenagem e condições climáticas bastante amenas e ideais para um desenvolvimento de espécies de plantas diversas. Nesta formação destaca-se a presença dos palmiteiros (Euterpe edulis). Também são espécies importantes a Garajuva (Buchenavia kleinii), a Peroba (Aspidosperma parvifolium) e a Canela-preta (Ocotea catharinensis) (SEVEGNANI, LAPS, SCHROEDER, 2013).

Dos $400 \mathrm{~m}$ até os $1.000 \mathrm{~m}$ está a Floresta Ombrófila Densa Montana. Presente em áreas onde o solo é um pouco mais profundo que no topo das elevações, possibilita a formação de uma vegetação com um dossel de no máximo 20m (IBGE, 2012), porém a altura das plantas vai diminuindo conforme mais acentuada fica a altitude e a inclinação dos terrenos. Como espécies de plantas que se destacam estão, como citados na formação Submontana, os palmiteiros, a Peroba e a Canela-preta, além do Tanheiro (Alchornea triplinervia) e o Pau-óleo (Copaifera trapezifolia) (SEVEGNANI, LAPS, SCHROEDER, 2013).

Na parte mais extremada no que se refere à altitude, na Floresta Ombrófila, se encontra a formação Altomontana. Em Santa Catarina possui o nome popular de Mata Nebular, por estar constantemente sob influencia de uma camada de neblina (KLEIN, 1978), formada pela ascendência do ar quente e úmido vindo do mar no encontro com os paredões da Serra Geral, que conforme sobe vai se resfriando adiabaticamente até encontrar o ponto de saturação e condensar. Presente em altitudes superiores aos $1.000 \mathrm{~m}$, estão sob clima de montanha, sendo o frio um importante condicionante.

Estas florestas Altomontanas, ou Nebulares, possuem uma fisionomia peculiar, de modo geral com árvores baixas e de troncos retorcidos (KOEHLER, 2001). É uma formação muito particular, rica em espécies endêmicas, por causa das condições ambientais responsáveis pelo seu desenvolvimento serem muito particulares, como a altitude, solo incipiente, presença de neblina e acentuada inclinação do terreno. Por esses motivos a floresta Altomontana possui um valor científico de grande estima (KOEHLER, 2001). 
A vegetação é constituída de matinhas baixas e densas, formada por árvores tortuosas e medianas (KLEIN, 1978). Destaca-se espécies de plantas como Gramimunhas (Weinmannia paulliniifolia), Pau-desanta-rita (Laplacea fruticosa) e Samambaias (Gleichenia spp) (SEVEGNANI, LAPS, SCHROEDER, 2013). Vale destacar as plantas do gênero Gunnera, que são muito características, por suas folhas gigantes, bastante comum nas partes mais altas e íngremes das escarpas da Serra.

No alto do planalto meridional sul brasileiro estão presentes duas formações distintas: a Floresta Ombrófila Mista, popularmente chamada de Mata de Araucária e as Estepes, também chamadas de Campos do Sul do Brasil. A Mata de Araucária compreende boa parte da superfície do Planalto, caracterizada por ter como dossel a espécie que dá o seu nome, a Araucária ou Pinheiro do Paraná (Araucaria angustifólia). Essa formação se encontra em seu “clímax climático” (IBGE, 2012).

Por fim, junto das Matas de Araucária, estão as Estepes. Formação condicionada pelo clima, que nessa porção do estado é considerado frio com vários meses onde a média da temperatura não passa os $15^{\circ} \mathrm{C} \mathrm{e}$ pelo solo incipiente e litólico, não possibilitando o desenvolvimento de uma vegetação exuberante, e sim, gramíneas (IBGE, 2012). Nas áreas de campos da Serra Geral encontra-se o Capim-caninha (Andropogon lateralis) e plantas de gênero Rhysehospora e Seleria. Outra forte característica dos campos é a presença de turfeiras formadas principalmente por musgos (Sphagnun spp.) e também da Samambaia-dos-banhados (Bleehnum imperiale).

\section{Resultados e Discussões}

Conforme Furlan (2011) o perfil é uma projeção do que se vê num plano. Eles podem ser utilizados para diversos estudos, sendo que na Biogeografia, que é o caso deste artigo, ilustram as relações entre a topografia e a distribuição horizontal das espécies vegetais, bem como o modo que seus portes vão se apresentando conforme a amplitude altimétrica.

No perfil fitofisionômico (figura 1) o esquema de representação da vegetação segue o mesmo padrão do Manual Técnico da Vegetação Brasileira, elaborado pelo IBGE. No perfil estão representadas as diferentes formações, de leste para oeste, que compõe a vegetação original, antes das devastações para exploração da madeira e posterior uso para o plantio.

Junto ao litoral catarinense, há as áreas de formações pioneiras, ou seja, uma vegetação de primeira ocupação de caráter edáfico, ocupando terrenos jovens, formados pelas sucessivas deposições de origem marinha, fluvial ou eólica (IBGE, 2012). As plantas destas áreas se adaptaram a fatores ecológicos 
XVII Simpósio Brasileiro de Geografia Física Aplicada

I Congresso Nacional de Geografia Física
OS DESAFIOS DA GEOGRAFIA FÍSICA NA FRONTEIRA DO CONHECIMENTO

Instituto de Geociências - Unicamp

Campinas - SP

28 de Junho à 02 de Julho de 2017

extremos e adversos, como a salinidade do solo e os constantes e severos ventos, típicos das regiões litorâneas.

Atualmente as formações vegetais se apresentam de maneira bastante diferenciada se comparada ao que já foi no passado. Estas alterações foram feitas em detrimento da exploração de madeiras nobres, como a peroba, cedro e outras e posterior uso agrícola. Este fato modificou a paisagem local, onde áreas florestadas foram substituídas por uso agrícola, com plantio, principalmente de arroz, nas áreas mais planas, banana, fumo e milho nas áreas mais elevadas. Contudo, alguns remanescentes da vegetação original se mantêm preservados ou em estágio avançado de sucessão vegetal.

A Formação Edáfica de Primeira Ocupação situa-se ao longo do litoral, nas planícies fluviais e ao redor das depressões aluviais (pântanos, lagunas e lagoas), ou seja, frequentemente em terrenos instáveis. Tratase de uma vegetação de primeira ocupação de caráter edáfico, que ocupa terrenos rejuvenescidos pelas seguidas deposições de areias marinhas nas praias e restingas, os aluviões fluvio-marinhos nas embocaduras dos rios e os solos ribeirinhos aluviais e lacustres.

$\mathrm{Na}$ área de estudo essas formações encontram-se próximas ao mar e estão subdivididas em:

- Comunidades Aluviais: de influência aluvial, que refletem os efeitos das cheias dos rios e lagos nas épocas chuvosas ou então das depressões alagáveis todo o ano. No perfil topográfico está situada ao redor de um lago, entre os quilômetros 38 a 40. Como esses terrenos esporadicamente estão alagados a vegetação está preservada, pois não há como ocupar essas áreas.

- Restinga: de influência marinha, ocorre em meio às dunas, ou seja, terrenos arenosos. Essas espécies vegetais adaptaram-se a fatores ecológicos extremos, como salinidade do ar e do solo, além do constante vento e do spray marinho. Na área de estudo encontra-se, predominantemente, na faixa entre os quilômetros 40 a 46, ou seja, entre as comunidades aluviais e o oceano. Atualmente está relativamente preservada, porém em observações de imagens geradas por satélite, nota-se manchas de silvicultura, além de haver edificações e terrenos loteados nessas áreas, o que pode indicar um futuro aumento da ocupação humana. 

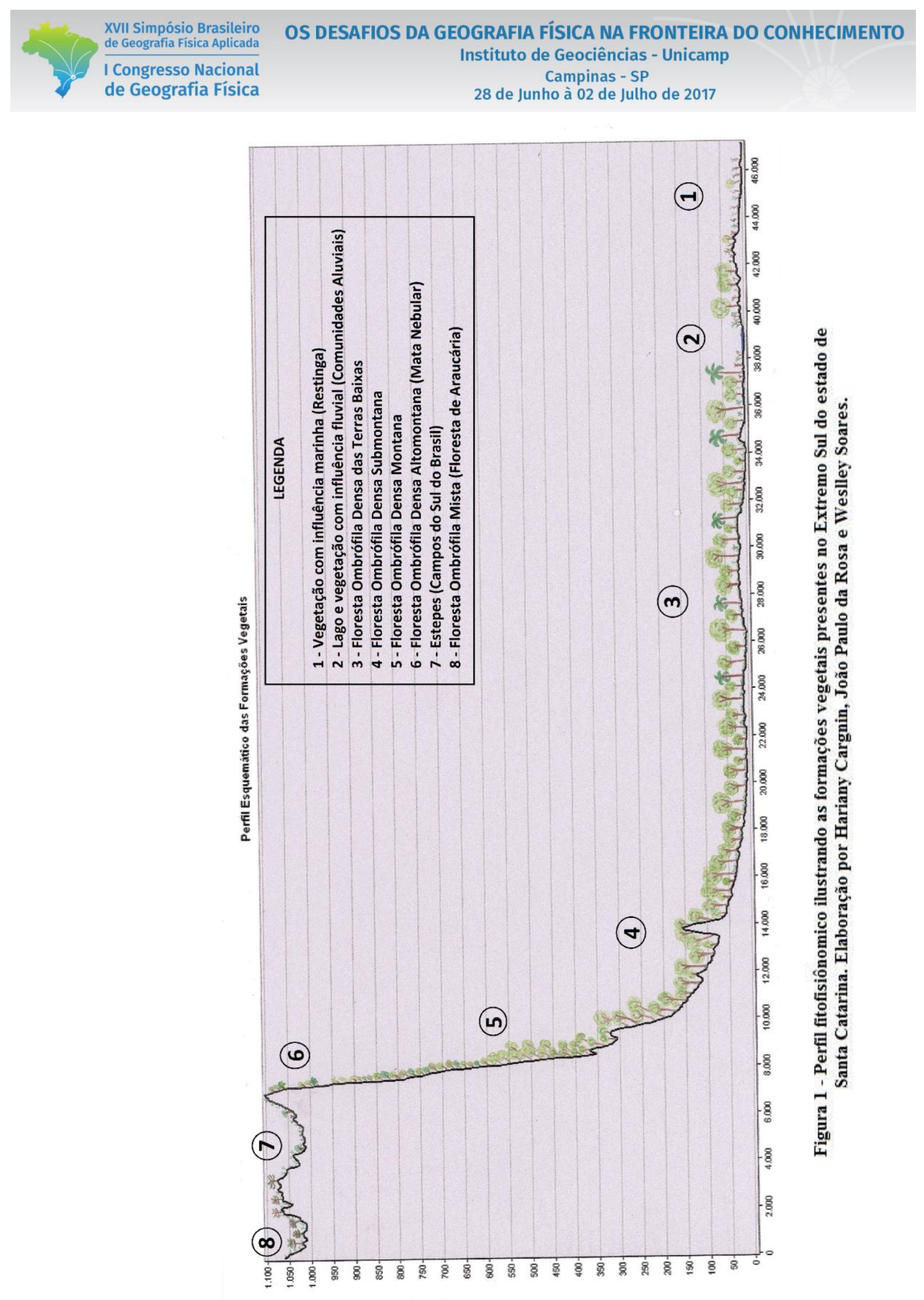


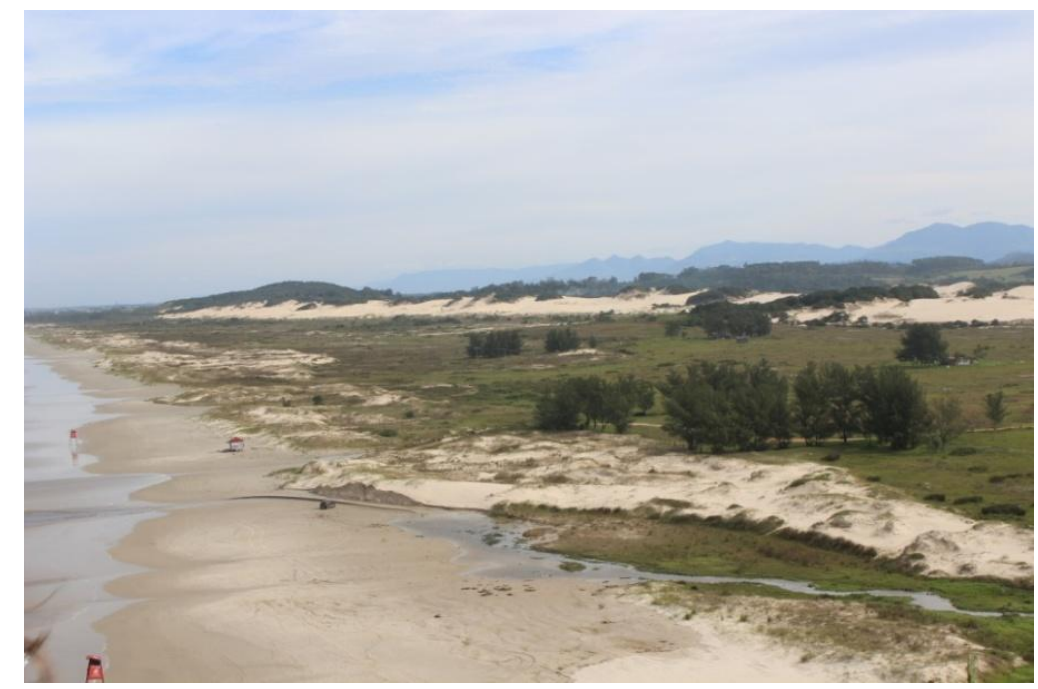

Figura 2 - Observar a zona de Restinga ou Formação Edáfica de Primeira Ocupação com Influência Marinha. Foto: Yasmim Fontana. Data: 29/04/2016.

A Floresta Ombrófila Densa das Terras Baixas está localizada em áreas de terrenos sedimentares terciário/quaternário, terraços, planícies e depressões aplainadas não suscetíveis à inundação, na faixa de altitude de $5 \mathrm{~m}$ a $30 \mathrm{~m}$ do nível do mar.

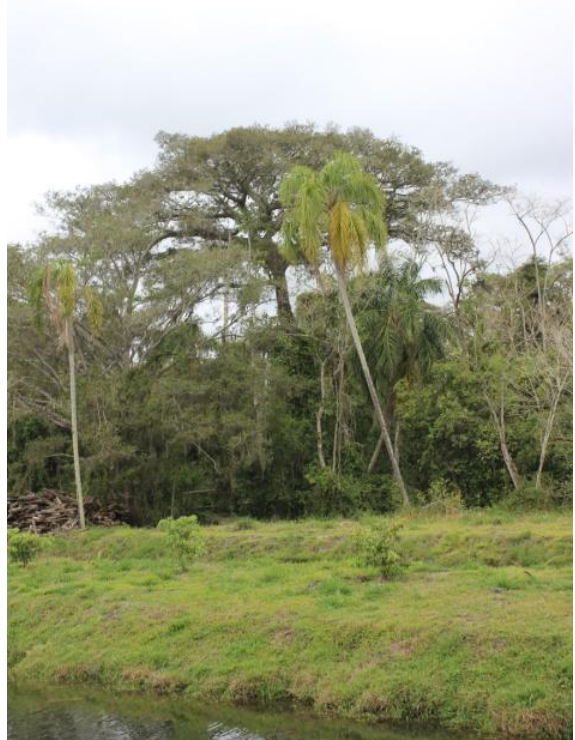

Figura 3 - Observar formação Terras Baixas preservada no Parque Ecológico Municipal de Maracajá (SC). Foto: Yasmim Fontana. Data: 01/09/2016. 


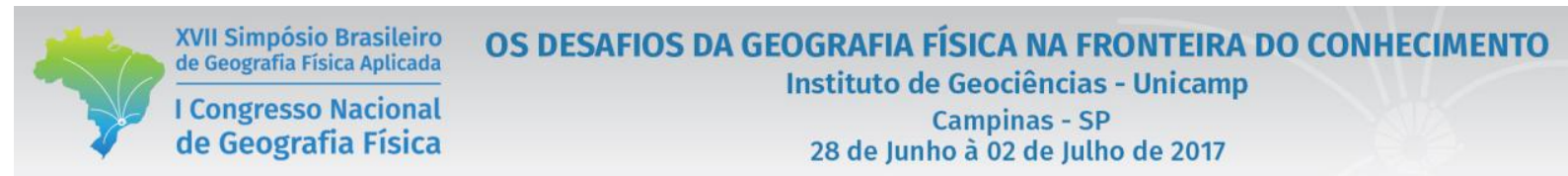

No perfil fitofisionômico de vegetação original situa-se, predominantemente, na faixa que vai do quilômetro 38 ao 16, ou seja, quase todo o compartimento de relevo planície costeira. Porém, atualmente, encontra-se bastante modificada e devastada por causa das atividades agrícolas, dando lugar a plantações de arroz.

A Floresta Ombrófila Densa Submontana, situada nas encostas de planaltos e serras a altitudes entre 30m a em torno de $400 \mathrm{~m}$. No perfil topográfico encontra-se predominantemente entre os quilômetros 16 e 8 . Assim como ocorre com a formação Montana, apresenta-se preservada, muito por causa da acentuada inclinação do terreno, na escarpa da Serra Geral.

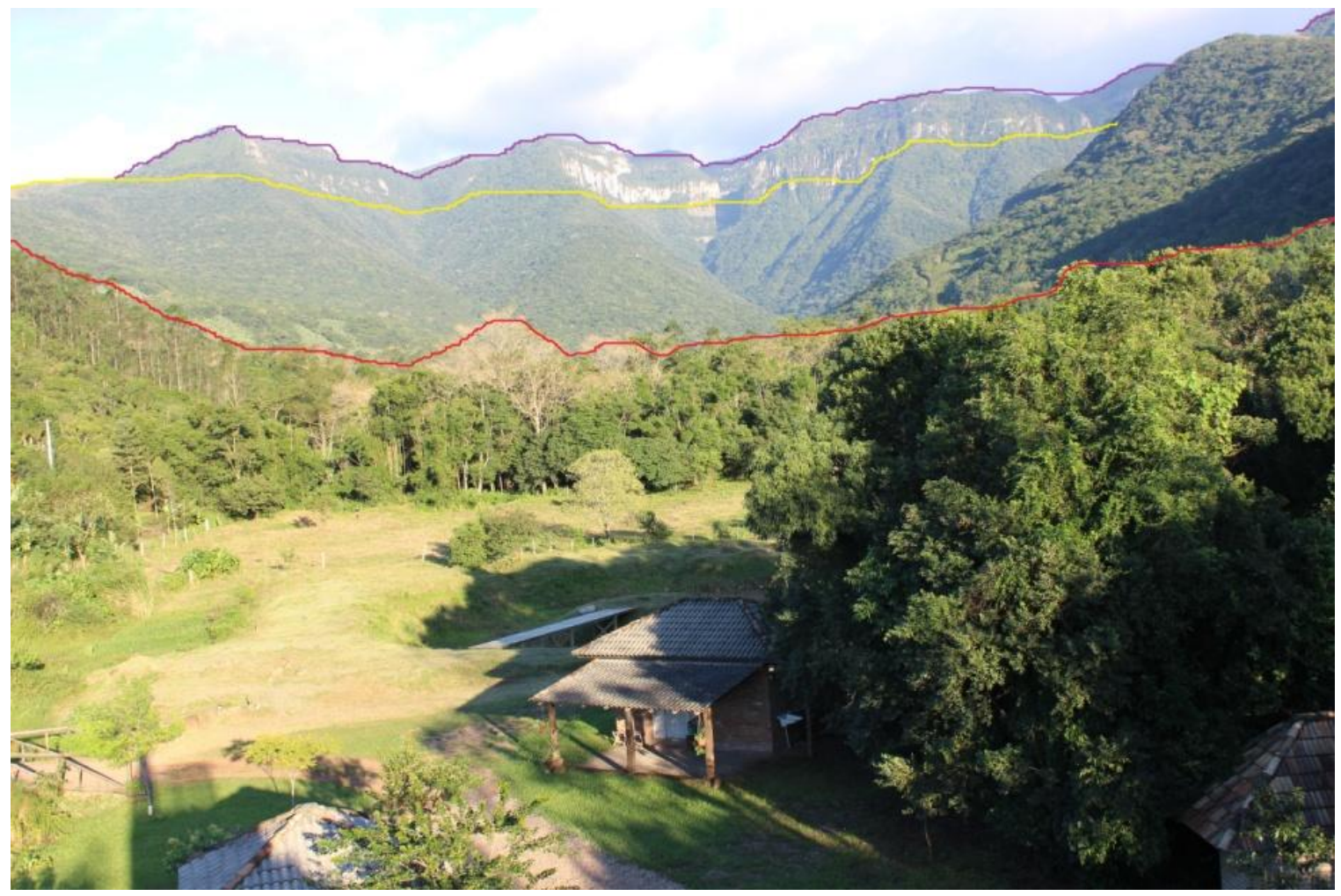

Figura 1 - Observar a formação de Floresta Ombrófila Densa das Terras Baixas em primeiro plano (abaixo da linha vermelha); formação Sub-montana (entre as linhas vermelha e amarela); formação Montana e Altomontana ou Nebular (entre as linhas amarela e lilás). Foto: Yasmim Fontana. Data: 29/04/2016.

A Floresta Ombrófila Densa Montana, possui altitudes de 400m até em torno dos $1.000 \mathrm{~m}$. Já a formação Altomontana abrange as escarpas com mais de $1.000 \mathrm{~m}$, onde em Santa Catarina é dado, regionalmente, o nome de Floresta Nebular, pois sofre a influência constante da neblina. Abriga gêneros vegetais característicos como a Gunnera. No perfil, encontra-se na escarpa da Serra Geral, predominantemente entre os quilômetros 8 e 6 . Devido à acentuada inclinação dos terrenos a sua abrangência está preservada atualmente. 
As Estepes (Campos do Sul do Brasil) são formações vegetais predominantemente campestres, com gramíneas, arbustos e árvores esparsas, da zona temperada com precipitação pluviométrica distribuída ao longo de todo o ano. No Brasil podem-se encontrar Estepes em dois amplos e distintos ambientes: os campos meridionais do Rio Grande do Sul e no Planalto das Araucárias, em Santa Catarina.

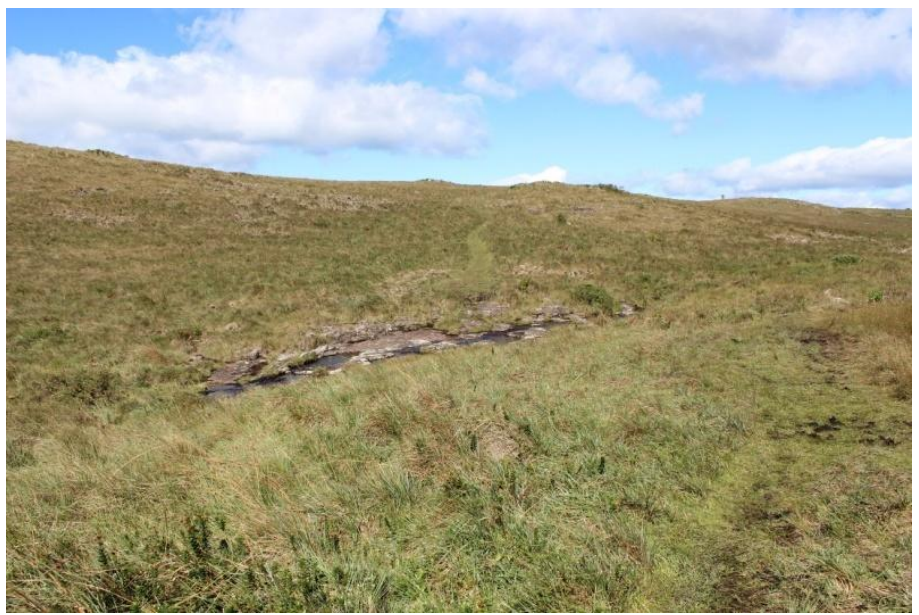

Figura 5 - Observar formação das Estepes (Campos do Sul do Brasil). Foto: Yasmim Fontana. Data: 30/04/2016.

$\mathrm{Na}$ área de estudo deste trabalho as Estepes situam-se no alto do planalto da Serra Geral, correspondendo os quilômetros 8 ao 4 no perfil topográfico, juntamente com a formação de Floresta Ombrófila Mista. Atualmente encontra-se preservada, porém sofreu modificações em virtude das queimadas, o que gerou uma seleção de suas espécies vegetais.

A Floresta Ombrófila Mista Altomontana, também conhecida como Mata de Araucária. Ocorre em climas frios onde o solo tem espessura capaz de suportar árvores. Encontra-se no planalto da Serra Geral e em áreas disjuntas da Serra do Mar e Serra da Mantiqueira. No perfil fitofisionômico está situada predominantemente no alto do Planalto, nos quilômetros 4 ao 0. 


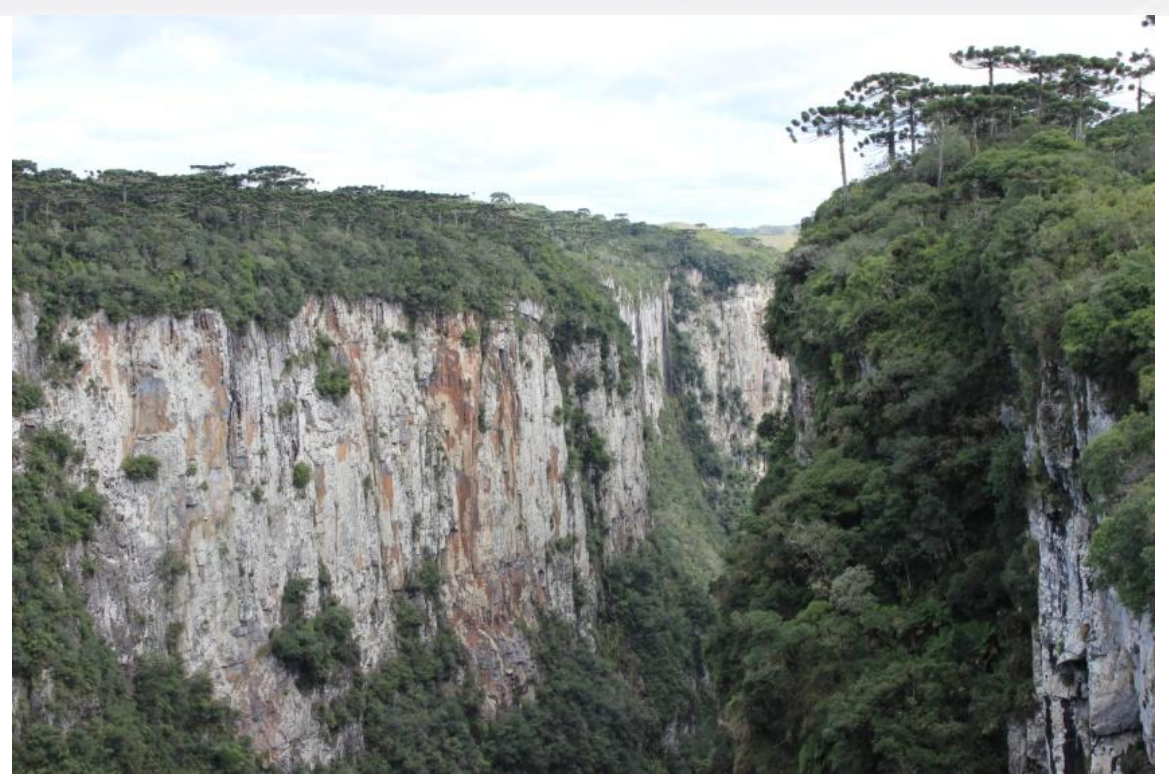

Figura 6 - Canyon Itaimbezinho. Observar formação Floresta Ombrófila Mista no alto do planalto. Foto: Yasmim Fontana. Data: 30/04/2016.

\section{Conclusão}

O uso do perfil como ferramenta de representação da vegetação é pertinente, pois ilustra de forma muito clara as diferentes estruturas das formações vegetais, sua distribuição espacial e suas relações com a topografia.

A representação do perfil fitofisionômico pode ser também um importante instrumento didático para o ensino da vegetação, dada a sua capacidade de ilustrar a relação entre a topografia e a fisionomia das formações vegetais.

Este tipo de trabalho nos permite observar como era a vegetação original da área e como as modificações ao longo tempo e espaço transformaram a paisagem, tanto pelas diferentes características físicas, quanto pela ação antrópica como agente de devastação. Em outras abordagens o perfil fitofisionômico permite um acompanhamento do atual cenário ecológico, evidenciando a importância de preservar os remanescentes de vegetação para a manutenção da diversidade ecológica.

\section{Bibliografia}

FURLAN, S. A. Técnicas de Biogeografia. In: VENTURE, L. A. B. (Org.). Geografia: práticas de campo, laboratório e sala de aula. São Paulo: Editora Sarandi, 2011. Cap. 6. p. 136-170.

IBGE. Manual técnico da vegetação brasileira. $2^{\mathrm{a}}$ ed. Rio de Janeiro, 2012. 
28 de Junho à 02 de Julho de 2017

KLEIN, R.M. 1978. Mapa fitogeográfico do Estado de Santa Catarina. Flora Ilustrada Catarinense, Itajaí, 24 p.

KOEHLER, A.. Floresta Ombrófila Densa Altomontana: Aspectos Florísticos e Estruturais do Componente Arbóreo em Diferentes Trechos da Serra do Mar, PR. 2001. 89 f. Dissertação (Mestrado) - Curso de Engenharia Florestal, Universidade Federal do Paraná, Curitiba, 2001. Disponível em: <http://acervodigital.ufpr.br/bitstream/handle/1884/25192/D KOEHLER, ALEXANDRE.pdf;jsessionid=EB15C05E64A56B2CFA4F60A8878F25D6?sequence=1>. Acesso em: 09 mar. 2017.

SEVEGNANI, L.; LAPS, R. R.; SCHROEDER, E. A Vertente Atlântica. In: SEVEGNANI, Lucia; SCHROEDER, Edson (Org.). Biodiversidade Catarinense: Características, Potencialidades, Ameaças. Blumenau: Edifurb, 2013. $\begin{array}{llllll}\text { Cap. } & 5 . & \text { p. } & 93-133 & \text { Disponível }\end{array}$ <http://ciram.epagri.sc.gov.br/ciram_arquivos/arquivos/iff/livros/biodiversidade.pdf>. Acesso em: 09 mar. 2017. 